\title{
Oncomodulin and macrophages derived factors in pancreas injury and development paradigms
}

\author{
Joël Fleury Djoba Siawaya ${ }^{1,2^{*}}$, Carmen Capito ${ }^{1}$, Raphael Scharfmann ${ }^{1}$ \\ ${ }^{1}$ Centre de Recherche "Croissance et Signalisation”, Inserm Unité-845, Faculté de Médecine Paris 5, Paris, France; \\ *Corresponding Author: joelfleury@yahoo.com, joel.djoba@gmail.com \\ ${ }^{2}$ Laboratoire National de Santé Publique, Unité de Recherche, Libreville, Gabon
}

Received 6 December 2012; revised 14 January 2013; accepted 5 February 2013

\begin{abstract}
Prior studies in the optic nerve injury paradigm showed conflicting data regarding production and significance of the $\mathrm{Ca}^{2+}$-binding protein oncomodulin (OCM). Some have shown its potent axon-regenerative or-growth attribute, where other showed little to no effect. We show here that pancreas inflammation lead to macrophages infiltration that produce $\mathrm{OCM}$ and inflamed tissues that express OCM receptors in vivo. In culture OCM has a cytostatic effect on embryonic pancreas explants. Secretory products of zymosanactivated macrophages are cytotoxic and factors derived from non-activated macrophages seem to promote pancreas development. It is our view that $O C M$ is involved in protective injury response that allows through metabolism slowing sub-lethally injured cells to undergo recovery.
\end{abstract}

Keywords: Macrophages; Oncomodulin; Inflammation; Pancreas

\section{INTRODUCTION}

The pancreas is a gland, with both endocrine and exocrine features. The endocrine parts of the pancreas consist of cell clusters called islets of langerhans. There are four main cell types in the islets: $\alpha$ cells (glucagons secreting cells), $\beta$ cells (insulin secreting cells), $\delta$ cells (somatostatin secreting cells), and PP cells (pancreatic polypeptide secreting cells) [1]. In contrast to the endocrine pancreas, which secretes hormones the exocrine pancreas through acinar cells produces alkaline fluid and digestive enzymes including trypsin chymotrypsin, pancreatic lipase and pancreatic amylase.

The immune system is in the core of the mechanisms leading to the development of both form of diabetes. In type one diabetes T-cell-mediated autoimmune response against beta cells appears to be the main cause for the loss of the insulin-producing beta cells leading to insulin deficiency whereas, in type 2 diabetes obesity related pro-inflammatory response is involved in the development of insulin resistance.

Although treatment options for the type 1 diabetes remain principally limited to insulin replacement therapy, today new avenues such as islet cell regeneration, regrowth of host own islet cells or islet transplantation are being explored. The principal roadblock to the widespread application of these new therapeutic approaches are the molecular mechanisms and relevant growth factors implicated in endocrine pancreas development which are yet to be fully elucidated and which are required to devise techniques to generate insulin-producing beta cells.

Macrophages secrete a variety of biologically active molecules that can have both positive and negative effects on tissue depending of the circumstances. Macrophages derived factors have been shown to play and influence the mechanism leading to injury healing and tissues regeneration. Recently, it has been shown that factors secreted by tissue-infiltrated macrophages such as oncomodulin (OCM), a small, $\sim 12 \mathrm{kDa}$ calcium-binding protein in the parvalbumin family had a regenerative and growth promoting effect on retinal ganglion cell axon [2-4]. Furthermore, the regeneration of beta cells after injury has lead to the concept that factors derived from injury related immune response (or inflammation) might be involved beta cells progeny differentiation and maturation [5].

We therefore investigated pancreas injury and the effect of the macrophages derived factors including $\mathrm{Ca}^{2+}$ binding protein oncomodulin (OCM) on pancreas development. Pancreas duodenum homeobox-1 (Pdx-1) that regulates pancreas development during embryogenesis [6], neurogenin3 (Ngn3) required for the development of endocrine pancreas [7], insulin and amylase were used as indicators of effects. 


\section{METHODS}

\subsection{Partial Duct Ligation (PDL) of Adult Mice Pancreas}

Pancreas inflammation was induced by partial duct ligation (PDL) of adult BALB/C mice (Centre d'élevage René Janvier, Le Genest, France) pancreas as described in previous reports [5].

\subsection{Immunohistochemistry}

Immunohistochemistry and quantification - tissues were fixed in $10 \%$ formalin, pre-embedded in agarose gel $(4 \%$ of type VII low gelling temperature agarose (SigmaAldrich) $)$ and embedded in paraffin. Sections ( $4 \mu \mathrm{m}$ thick) were collected and processed for immunohistochemistry, as described previously [8,9]. Antibodies were used at the following dilutions: rat monoclonal to macrophage (Abcam; 1/200), rabbit polyclonal to oncomodulin (Abcam; 1/1000), mouse anti-human insulin (Sigma-Aldrich, 1/2000), rabbit anti-amylase (Sigma-Aldrich, 1/300), guinea pig anti-insulin (Dako, Trappes, France; 1/500), mouse anti-BrdUrd (Amersham Biosciences, Buckinghamshire, UK; 1/2). Enzyme-conjugated secondary antibody was: HRP-conjugated anti-rat anti-body. The fluorescent secondary antibodies were: fluorescein isothiocyanate anti-rabbit antibody (Jackson Immuno research, Baltimore, MD; 1/200), Texas Red anti-mouse antibody (Jackson ImmunoResearch; 1/200) and Alexa Fluor antirabbit antibody (Biogenex, San Ramon, CA; 1/400). Nuclei were stained in blue using Hoechst $33342(0.3 \mu \mathrm{g} / \mathrm{ml}$, Invitrogen). The diaminobenzidine (DAB) was used as substrate for HRP-conjugated anti-body. Photographs were taken using a fluorescence microscope (Leica, Leitz DMRB, Reuil-Malmaison, France) and digitized using a Hamamatsu (Middlesex, NJ) C5810 cooled 3CCD camera.

Oncomodulin ligand binding assay (adapted fromCaroline Brennan and Jez Fabes protocol, Science's STKE 2003) [10].

Slides of snap freeze dissected adult mice pancreas (inflamed and non-inflamed) were rehydated for ten minutes and incubated for with alkaline phosphatase oncomodulin fusion protein (AP-OCM), alkaline phosphatase (AP) or with an OCM receptor ligand and OCM competitor (PEP) was used to verify the specificity of AP-OCM to OCM receptor binding. After washing (with HBS), tissues were fixed for 90 seconds (acetone-formaldehyde fixative), washed again and incubated at $65^{\circ} \mathrm{C}$ for one hour to reduce endogenous AP activity. Slides were then rinsed in AP reaction buffer (Tris-HCL: 100 $\mathrm{mM}$; $\mathrm{NaCl}: 100 \mathrm{mM}$ and $\mathrm{MgCl}_{2}: 50 \mathrm{mM}$ in distilled water) and incubated with AP staining buffer (nitro blue tetrazolium chloride/5-bromo-4-chloro-3-indoyl phosphate toluidine salt (BCIP/NBT)).

\subsection{Macrophage Culture and Production of Macrophages Conditioned Medium}

Macrophages conditioned medium was produced as described by Y. Q. Yin et al. [11] with some adjustment. Succinctly, rat alveolar macrophages (NR8383) from American Type Cell Culture, (Manassas, VA) were maintained for few days in $15 \%$ fetal calf serum enriched F-12K medium (Life Technologies, Gaithersburg, MD) with $1 \%$ penicillin-streptomycin at $37^{\circ} \mathrm{C}$ in a humidified $5 \% \mathrm{CO}_{2}$ incubator. Macrophages were then washed in serum-free F-12K medium and centrifuged down to remove serum components. Resuspended macrophages (in F-12K medium) were either were treated by with Zymosan $(1.25 \mathrm{mg} / \mathrm{ml}$, final concentration incubated over night at $37^{\circ} \mathrm{C}$ in $5 \% \mathrm{CO}_{2}$ ) or were left untreated. Culture supernatants were collected, centrifuged $(1500 \times \mathrm{g})$ for 10 min and put through a $0.2 \mu \mathrm{m}$ low-protein binding filter (Pall-Gelman Laboratory, Ann Arbor, MI) before addingprotease inhibitors (Complete, Roche, Indianapolis, IN). Some of the Zymosan Macrophage-conditioned medium was fractioned by means of a $3 \mathrm{kDa}$ molecular weight cutoff ultrafiltration membrane (Amicon/Millipore, Bedford, MA) and stored at $-80^{\circ} \mathrm{C}$ until it was use.

\subsection{Pancreas Explants Procurement and Culture}

Pregnant Wistar rats were obtained from Janvier breeding center (Centre d'élevage René Janvier, Le Genest, France) and embryos harvested at E13. Embryos were then dissected and embryonic dorsal pancreas retrieved as previously described [8]. Dorsal pancreatic explants were laid on white $0.45 \mathrm{M}$ FHLC membrane (Millipore, St-Quentin-en-Yve-lines, France) at the airliquid interface in sterile multi-wells tissue culture plate (Becton Dickinson, Le Pont de Calais, France), containing $2 \mathrm{ml}$ of 1) control medium (F-12K modified medium enriched $15 \%$ of fetal calf serum and supplemented with penicillin-streptomycin (1\%), Hepes (0.01 M), non-essential amino acids ( $1 \mathrm{X})$ ); 2) control medium + OCM $(10 \mathrm{nM})$; 3) control medium + forskolin $(10 \mu \mathrm{M})$; 4) control medium + OCM (10 nM) + Forskolin; 5) nonactivated macrophages conditioned medium; 6) Zymosan activated macrophages conditioned medium. For culture macrophages conditioned mediums were supplemented as we did control for control medium. Cultures were maintained at $37^{\circ} \mathrm{C}$ in humidified 95\% air, 5\% $\mathrm{CO}_{2}$. Following culture, dorsal pancreatic explants were harvested for RNA extraction.

\subsection{RT-PCR and Q-PCR}

To determine the effect of macrophages derived fac- 
tors on dorsal pancreas growth, transcript levels of $\mathrm{Ngn}^{3+}$, Pdx-1 insulin1, amylase and DNA damage-inducible transcript 3 were quantified in pancreatic explants (E13) and after 3 days of culture with macrophages conditioned mediums (Zymosan-activated/-non activated), and OCM (-/+ forskolin), Total RNA was isolated using the Qiagen RNeasy Microkit (Qiagen, Courtaboeuf, France) and treated with DNase I to eliminate genomic contamination. $100 \mathrm{ng}$ each RNA sample was reverse transcribed as described above. Obtained cDNA was then diluted to $1 / 20$ and $5 \mu$ were used per PCR reaction. Each reaction consisted of a mix of Taqman ${ }^{\circledR}$ universal PCR master mix (Applied Biosystem) with primers specific for each gene (Applied Biosystem). Samples were run in a 7300 Fast real-time PCR system (Applied Biosystem, Paris, France). The instrument was set on universal thermal cycling protocol $\left(95^{\circ} \mathrm{C}, 10 \mathrm{~min}\right.$ followed by 40 cycles of $95^{\circ} \mathrm{C}$, $15 \mathrm{~s}$ and $\left.65^{\circ} \mathrm{C}, 1 \mathrm{~min}\right)$. Peptidylpropyl isomerase A was used as endogenous control. E16.5 pancreas cDNA was used as calibrator sample. The data were analyzed by comparative cycle threshold method and presented as the fold change in gene expression, normalized to a calibrator that equals a value of one [12].

\subsection{Statistical Analysis}

All statistical analysis were done using Prism software version 4.0. Genes' expression differences between groups were analyzed using the Bonferroni's Multiple Comparison Test followed by Dunnett's Multiple Com- parison Test. A p-value of 0.05 was judged significant.

\section{RESULTS}

\subsection{Upon Injury Infiltrated Macrophages Express Oncomodulin in a Timely Manner}

Pancreas injury and the subsequent inflammation were obtained through partial duct ligation (PDL) of adult mice pancreas. Immunohistochemistry analysis of inflamed pancreas section showed infiltrated macrophages to be OCM-positive (Figure 1). OCM signal in infiltrated macrophages was the strongest at day 7 after PDL. The signal subsequently weakened at day 14 and 30 after PDL (Figure 2).

\subsection{Oncomodulin Receptors Are Expressed in Inflamed Pancreatic Tissues}

To investigate the expression of OCM receptors in inflamed and non-inflamed pancreatic tissues, alka-linephosphatase (AP)-OCM fusion protein-binding assay was used alone or together with immunohistochemistry for ductular complexes (Muc 1) and insulin-positive cells. Data showed that there is a stronger and detectable expression OCM receptors in inflamed pancreatic tissues compared to non-inflamed tissues (Figure 3(a)). Using PEP an OCM receptor ligand and inhibitor, we were able to verify the specificity of the AP-OCM fusion protein-

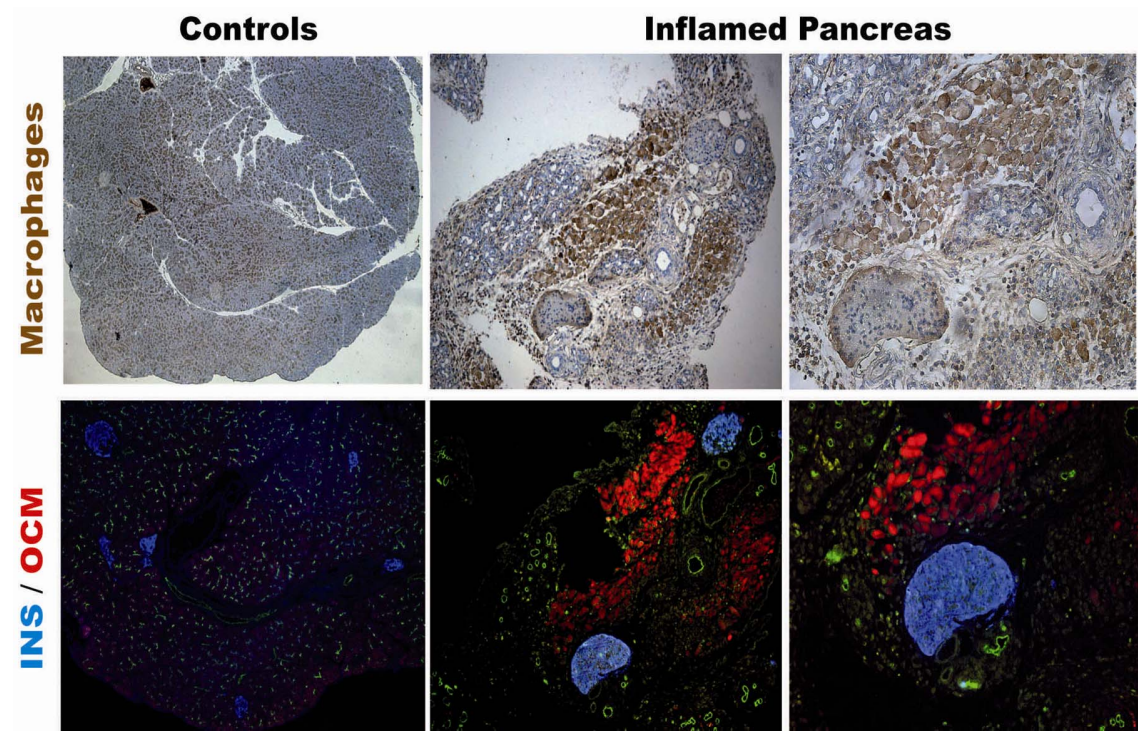

Figure 1. on injury infiltrated macrophages express OCM. Immunohistochemistry analysis of inflamed pancreas section after partial duct ligation (PDL) of adult mice pancreas. Infiltrated macrophages were revealed in brown using rat monoclonal to macrophage, HRP-conjugated antibody and diaminobenzidine (DAB). OCM producing macrophages were revealed in red (OCM), insulin-expressing cells were revealed in blue (INS) and ductular complexes in green (MUC1) by fluorescent immunohistochemistry. 

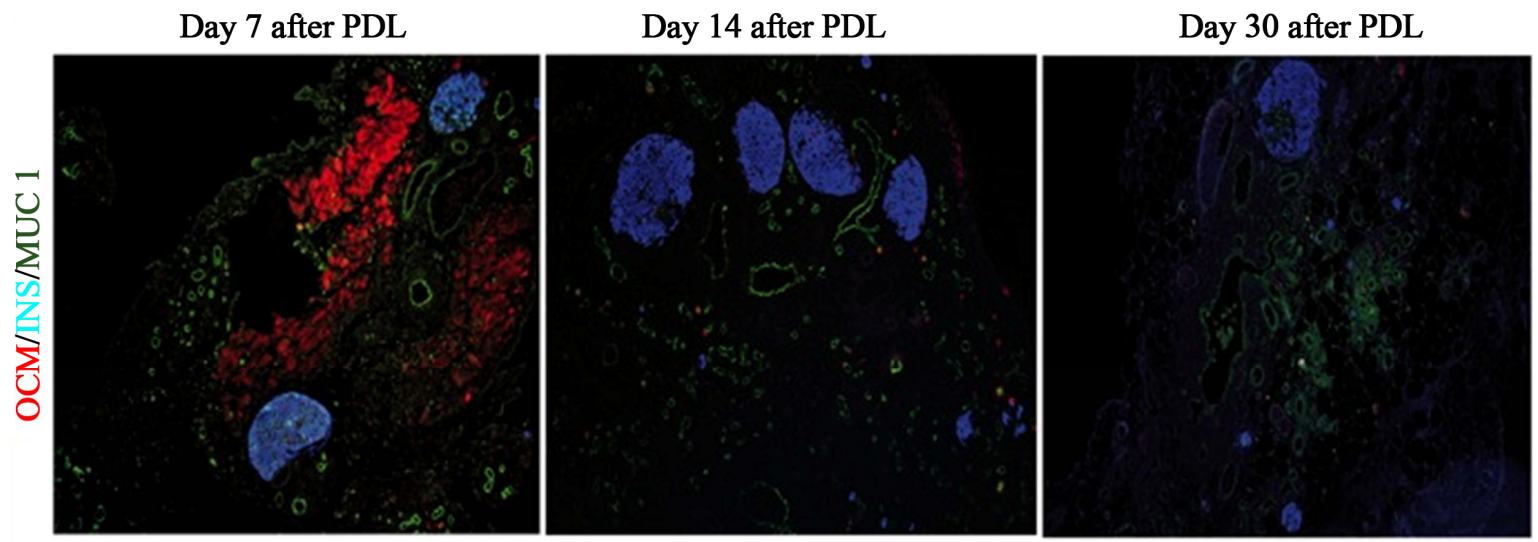

Figure 2. Expression of OCM in injured pancreas is done in a timely manner. In 8-week-old BALB/C mice, the duct that connects pancreatic tail and duodenum was ligated, and the PDL pancreas at day 7, 14, and 30 (PDL D7) were compared by immunohistochemistry for oncomodulin (OCM), ductular complexes (Muc 1) and insulin + cells.

(a)

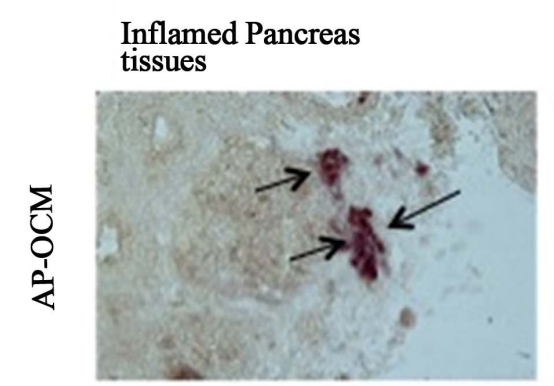

\section{Inflamed Pancreas tissues}
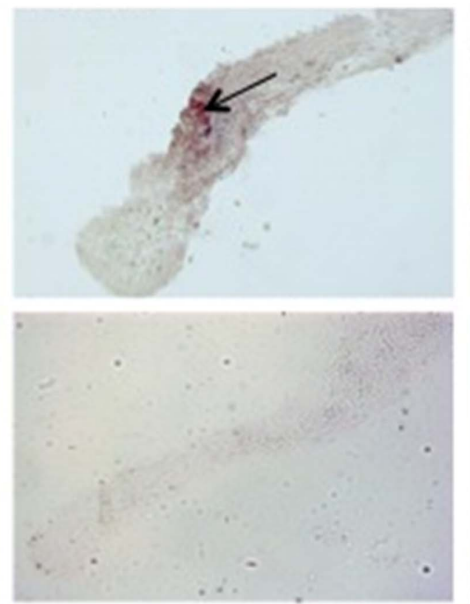

$\mathrm{AP}-\mathrm{OCM}+\mathrm{PEP}$

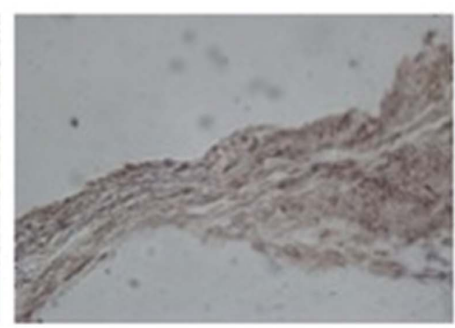

\section{Normal Pancreas} tissues
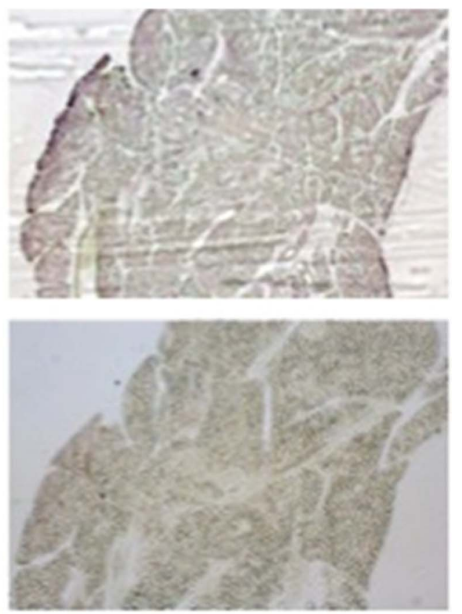

AP-OCM

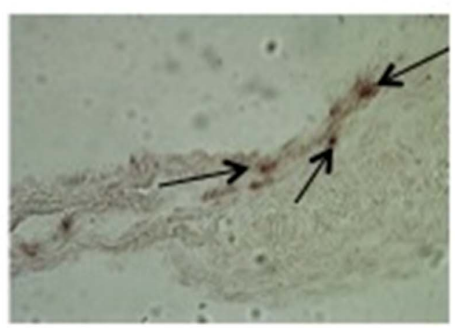

Figure 3. Inflamed pancreas tissues express OCM receptors. Alkaline phosphatase oncomodulin fusion protein (AP-OCM) and AP staining buffer were used to reveal OCM receptors expression in inflamed pancreatic tissues. Alkaline phosphatase (AP) was used as negative control. PEP an OCM receptor ligand and OCM competitor was used to verify the specificity of AP-OCM to OCM receptor binding. Arrows show AP-OCM bind to OCM receptors.

binding assay (Figure 3(b)).

\subsection{Bioactivity of Oncomodulin, Forskolin and Macrophages-Conditioned Medium on Selected Genes Expression (Invitro)}

To investigate whether or not OCM or macrophages derived factors in general have an effect on pancreatic cells, we cultured embryonic pancreas explants with OCM $(-/+$ forskolin) and macrophages-conditioned medium (zymosan treated and non-treated macrophages). The gene expression profile of three days cultured embryonic explants showed a drop in the expression of $\mathrm{Pdx}-1, \mathrm{Ngn}^{3+}$, insulin and amylase in pancreas explants cultured with 
OCM (-/+ forskolin) or zymosan treated macrophagesconditioned medium when compared to control explants or explant cultured with media from macrophages that had not been treated with zymosan (Figure 4). The analysis of variance (ANOVA) of Pdx-1, Ngn3+, insulin and amylase expression under the different experimental conditions showed that only the expression of the $\mathrm{Pdx}-1$ and the amylase gene was significantly different between the conditions $(\mathrm{p}<0.0005[\mathrm{Pdx}-1]$ and $\mathrm{p}<0.02$ [amylase] ANOVA). Further analysis using the Bonferroni's Multiple Comparison Test and Dunnett's multiple comparison post-test revealed details on the differences observed between the experimental conditions. Pdx-1 expression was significantly high in embryonic pancreas explants cultured with zymosan non-treated macrophages-conditioned medium when compared to control cultures ( $\mathrm{p}<0.05$; Dunnett's post test) and cultures with zymosan treated macrophages-conditioned medium ( $\mathrm{p}<0.01$; Bonferroni's post test) or OCM $(-/+$ forskolin) ( $\mathrm{p}<0.01$; Bonferroni's post test). The low expression Pdx-1 in OCM (-/+ forskolin) treated explants despite the good appearance of explants in culture suggests a cytostatic effect of OCM on embryonic pancreas explants whereas zymosan activated macrophages-conditioned medium seems to be cytotoxic (Figure 5). Contrarily to OCM and zymosan activated macro-phagesconditioned medium, macrophages-conditioned medium that had not been treated with zymosan seemed to enhance explants development.

Amylase expression was significantly high in explants cultured with zymosan non-treated macrophages-conditioned medium when compared to cultures including zymosan treated macrophages-conditioned medium $(\mathrm{p}<$ 0.05 ; Dunnett's post test) or OCM $(-/+$ forskolin) $(\mathrm{p}<$ 0.05; Dunnett's post test).

\subsection{Bioactivity of Oncomodulin, Forskolinon Pancreatic Cells Invitro Development}

At protein level, immunohistochemistry analysis of 7 days culture E13 rat explants showed non-significant differences in insulin and amylase positive cells between control explants and explants treated with forskolin and OCM(-/+ forskolin) (data not shown).

\section{DISCUSSION}

Here we established that upon pancreas injury infiltrated macrophages express OCM and inflamed tissues OCM receptors. Although this is the first time OCM and OCM receptors are put in evidence in injured pancreas, our results are consistent with previous report on OCM that show that OCM produced following tissues injury $[4,11,13]$.

Gene expression and visual analysis of cultured embryonic pancreas explants showed that activated macrophages derived factors are toxic to embryonic pancreas explants. Factors derived from non-activated macrophages-conditioned seem to enhance pancreatic cells development as showed by the increased Pdx-1 gene expression observed in explants cultured with non-activated macrophages-conditioned medium when compared to control cultures, cultures with zymosan treated macrophages-conditioned medium and cultures including OCM $(-/+$ forskolin). Activated macrophages are well known to produce cytotoxic factors [14-16]. Furthermore, invitro activation of macrophages has shown to cause the down regulation of the constitutively cystatin $\mathrm{C}$ secretion crucial for organs integrity [17]. Therefore it is not surprising that in the present study activated macrophage conditioned medium factors is detrimental to embryonic

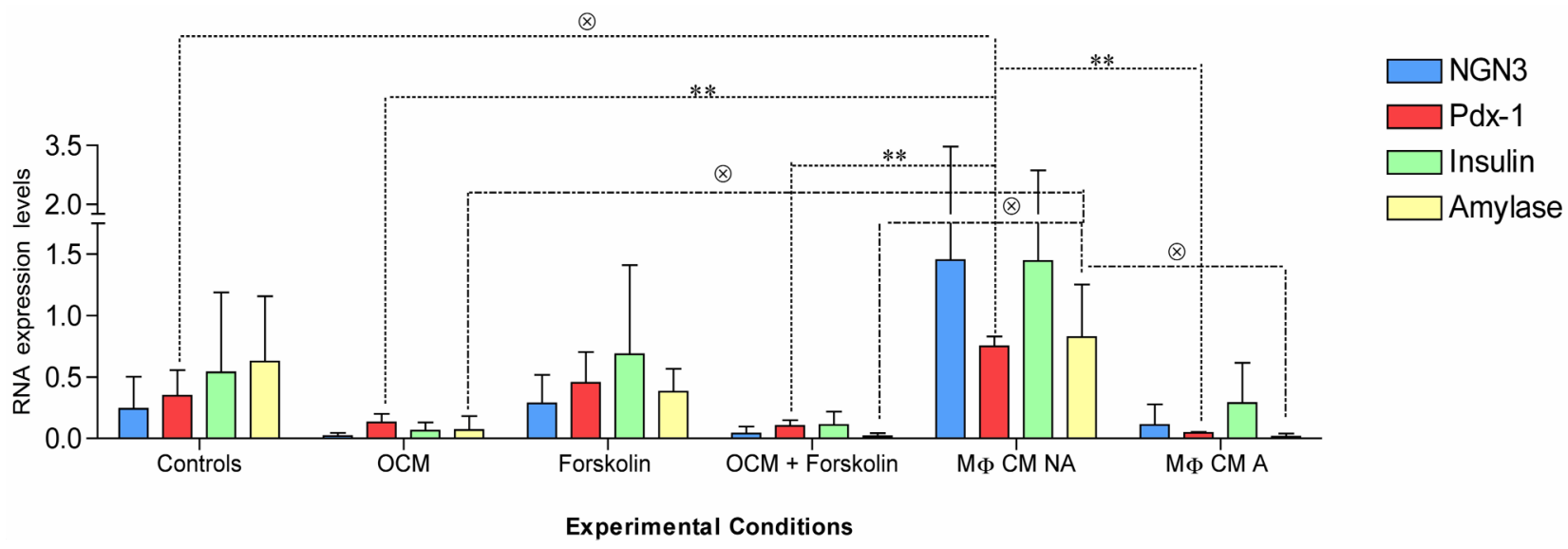

Figure 4. Pdx-1, Ngn3+, insulin and amylase RNA expression of E13 rat pancreatic explants after 3 days of culture with control medium (enriched F-12K modified medium), macrophages conditioned mediums (MФ CM) (Zymosan-activated (A)/-non activated (NA)), forskolin $(10 \mu \mathrm{M})$ and OCM $(10 \mathrm{nM})(-/+$ forskolin). Presented here are the results of three different experiments. $(*)$ Significant with Bonferroni's Multiple Comparison Test; $(\otimes)$ significant with the Dunnett's Multiple Comparison Test. 

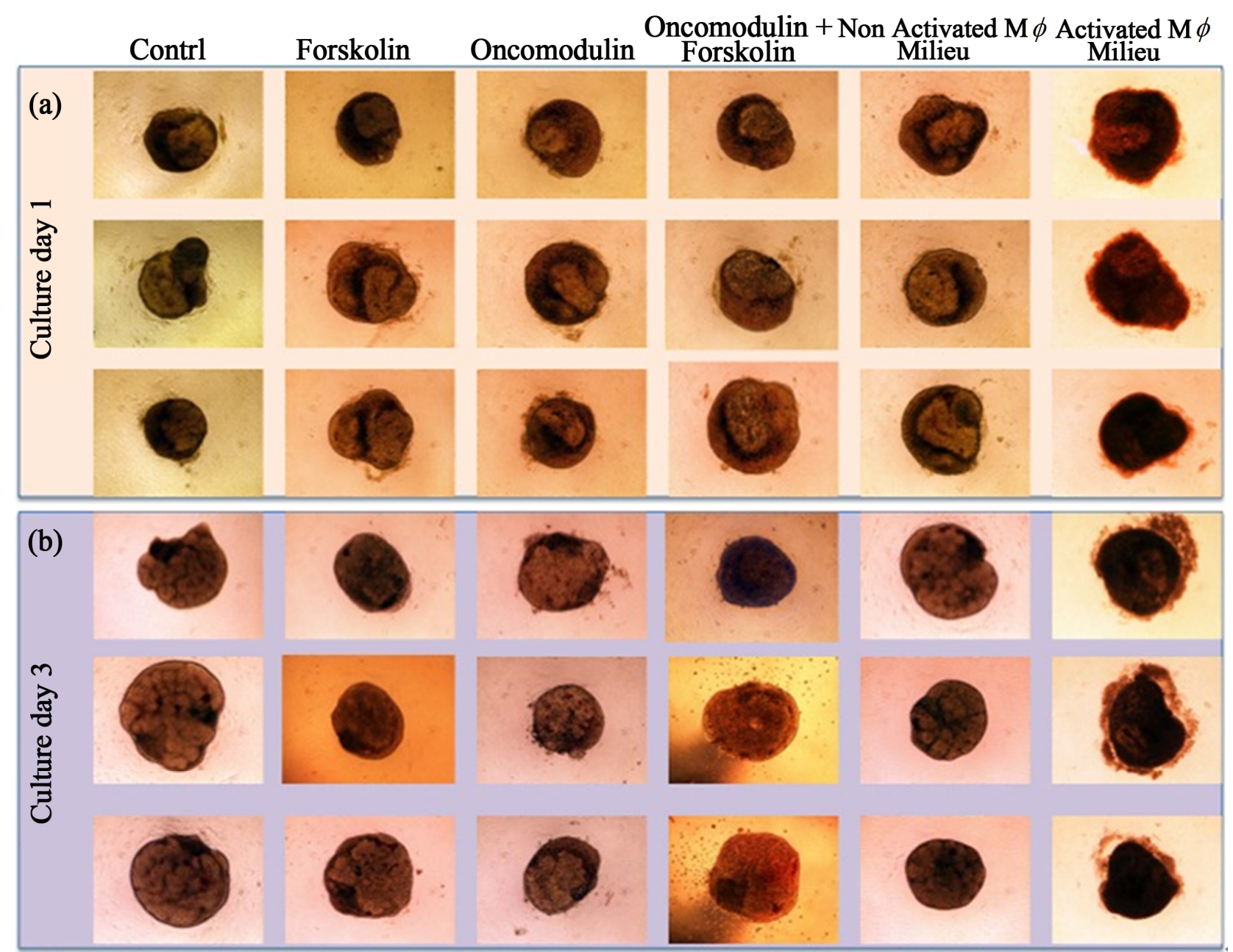

Figure 5. E13 rat pancreatic explants in culture, the suggested cytotoxic effect of Zymosan-activated macrophages. Day 1 (a) and day 3 (b) cultures of pancreatic explants in control medium (enriched F-12K modified medium), macrophages conditioned mediums (MФ CM) (Zymosan-activated (A)/-non activated (NA)), forskolin (10 $\mu \mathrm{M})$ and OCM $(10 \mathrm{nM})(-/+$ forskolin). The aspect of pancreatic explants cultured in Zymosan-activated MФ CM suggest a cytotoxic effect of activated macrophages on explants development.

pancreas explants growth in culture. The relative healthy growth of embryonic pancreas explants cultured with non activated macrophage conditioned medium and its increased Pdx-1 expression could be explained by growth factors constitutively secreted by non activated macrophages as demonstrated in a number of publication [18-20]. We speculate that in cultures with zymosan treated macrophages-conditioned medium, macrophages growth-promoting effect is masked by the much powerful cytotoxic effect.

Although OCM is produced by infiltrated macrophages during pancreas injury, it does not promote pancreatic cells development. Our observations suggest a cytostatic function of OCM. Because sustained increase of calcium after injury is well known preceding signals leading to cell death; metabolic inhibition has been shown to be strikingly protective against cell injury [21,22] and macrophage-mediated cytostasis has been proven
$[23,24]$. It is not far stretched to suggest that in the pancreas paradigm, the production of the $\mathrm{Ca}^{2+}$ biding protein OCM by macrophages observed during injury response was a regulatory mechanism triggered to limit cell death and associated cellular toxicity, through calcium regulation $[25,26]$ and reversible cytostasis [27]. In our view, OCM is more likely involved in protective injury response (slowing of metabolism) that allows sub-lethally injured cells to undergo recovery and regeneration. The expression OCM may only reflect a response to limit injury. This is not as Chalifour and al. reported the expression of OCM lead to an interruption of either cellular differentiation or organogenesis [28].

\section{CONCLUSION}

In vivo pancreas inflammation leads to the production of OCM by infiltrated macrophages and the expression OCM receptors inflamed tissues that express. It is our 
view that OCM may be involved in protective injury response that allows through metabolism slowing sublethally injured cells to undergo recovery.

\section{ACKNOWLEDGEMENTS}

We acknowledge Prof L. Benowitz and Dr. Y. Yin, from the Laboratory for Neuroscience Research in Neurosurgery, Harvard Medical School, Boston and Children's Hospital Boston for the free supply of OCM, alkaline-phosphatase (AP)-OCM fusion protein-binding and OCM receptor ligand protein (PEP) used in our experimentations.

This work was supported by the CODDIM Region Ile de France.

\section{REFERENCES}

[1] Linda, S.C. (2008) BRS physiology. 4th Edition, Lippincott Publishing, Philadelphia, 255-256.

[2] Benowitz, L. and Yin, Y. (2008) Rewiring the injured CNS: Lessons from the optic nerve. Experimental Neurology, 209, 389-398. doi:10.1016/j.expneurol.2007.05.025

[3] Benowitz, L.I. and Yin, Y. (2010) Optic nerve regeneration. Archives of Ophthalmology, 128, 1059-1064. doi:10.1001/archophthalmol.2010.152

[4] Yin, Y., Cui, Q, Gilbert, H.Y., Yang, Y., Yang, Z., Berlinicke, C., Li, Z., Zaverucha-do-Valle, C., He, H., Petkova, V., Zack, D.J. and Benowitz, L.I. (2009) Oncomodulin links inflammation to optic nerve regeneration. Proceedings of the National Academy of Sciences of the United States of America, 106, 19587-19592. doi:10.1073/pnas.0907085106

[5] Xu, X., D’Hoker, J., Stange, G., Bonne, S., De Leu, N., Xiao, X., Van de Casteele, M., Mellitzer, G., Ling, Z., Pipeleers, D., Bouwens, L., Scharfmann, R., Gradwohl, G. and Heimberg, H. (2008) Beta cells can be generated from endogenous progenitors in injured adult mouse pancreas. Cell, 132, 197-207. doi:10.1016/j.cell.2007.12.015

[6] Hui, H. and Perfetti, R. (2002) Pancreas duodenum homeobox-1 regulates pancreas development during embryogenesis and islet cell function in adulthood. European Journal of Endocrinology, 146, 129-141. doi:10.1530/eje.0.1460129

[7] Gradwohl, G., Dierich, A., LeMeur, M. and Guillemot, F. (2000) Neurogenin3 is required for the development of the four endocrine cell lineages of the pancreas. Proceedings of the National Academy of Sciences of the United States of America, 97, 1607-1611. doi:10.1073/pnas.97.4.1607

[8] Miralles, F., Battelino, T., Czernichow, P. and Scharfmann, R. (1998) TGF-beta plays a key role in morphogenesis of the pancreatic islets of Langerhans by controlling the activity of the matrix metalloproteinase MMP-2. Journal of Cell Biology, 143, 827-836. doi:10.1083/jcb.143.3.827

[9] Duvillie, B., Attali, M., Aiello, V., Quemeneur, E. and Scharfmann, R. (2003) Label-retaining cells in the rat pancreas: Location and differentiation potential in vitro. Diabetes, 52, 2035-2042. doi:10.2337/diabetes.52.8.2035

[10] Brennan, C. and Fabes, J. (2003) Alkaline phosphatase fusion proteins as affinity probes for protein localization studies. Science's STKE, 2003, PL2.

doi:10.1126/stke.2003.168.pl2

[11] Yin, Y.Q., Henzl, M.T., Lorber, B., Nakazawa, T., Thomas, T.T., Jiang, F., Langer, R. and Benowitz, L.I. (2006) Oncomodulin is a macrophage-derived signal for axon regeneration in retinal ganglion cells. Nature Neuroscience, 9, 843-852. doi:10.1038/nn1701

[12] Livak, K.J. and Schmittgen, T.D. (2001) Analysis of relative gene expression data using real-time quantitative PCR and the 2(-Delta Delta C(T)) Method. Methods, 25, 402-408. doi:10.1006/meth.2001.1262

[13] Li, Y., Irwin, N., Yin, Y., Lanser, M. and Benowitz, L.I. (2003) Axon regeneration in goldfish and rat retinal ganglion cells: Differential responsiveness to carbohydrates and cAMP. Journal of Neuroscience, 23, 7830-7838.

[14] Zacharchuk, C.M., Drysdale, B.E., Mayer, M.M. and Shin, H.S. (1983) Macrophage-mediated cytotoxicity: Role of a soluble macrophage cytotoxic factor similar to lymphotoxin and tumor necrosis factor. Proceedings of the National Academy of Sciences of the United States of America, 80, 6341-6345. doi:10.1073/pnas.80.20.6341

[15] Takeda, Y., Higuchi, M., Sugimoto, M., Shimoda, O., Woo, H.J., Shimada, S. and Osawa, T. (1986) The production of a cytotoxic factor by mouse peritoneal macrophages and macrophage hybridomas treated with various stimulating agents. Microbiology and Immunology, 30, 143-154

[16] Drysdale, B.E., Zacharchuk, C.M. and Shin, H.S. (1983) Mechanism of macrophage-mediated cytotoxicity: Production of a soluble cytotoxic factor. Journal of Immunology, 131, 2362-2367.

[17] Warfel, A.H., Zucker-Franklin, D., Frangione, B. and Ghiso, J. (1987) Constitutive secretion of cystatin C (gamma-trace) by monocytes and macrophages and its downregulation after stimulation. Journal of Experimental Medicine, 166, 1912-1917. doi:10.1084/jem.166.6.1912

[18] Assoian, R.K., Fleurdelys, B.E., Stevenson, H.C., Miller, P.J., Madtes, D.K., Raines, E.W., Ross, R. and Sporn, M.B. (1987) Expression and secretion of type $\beta$ transforming growth factor by activated human macrophages. Proceedings of the National Academy of Sciences of the United States of America, 84, 6020-6024.

[19] Van der Plas, M.J., van Dissel, J.T. and Nibbering, P.H. (2009) Maggot secretions skew monocyte-macrophage differentiation away from a pro-inflammatory to a proangiogenic type. PLoS One, 4, e8071. doi:10.1371/journal.pone.0008071

[20] Sugasawara, R.J., Cahoon, B.E. and Karu, A.E. (1985) The influence of murine macrophage-conditioned medium on cloning efficiency, antibody synthesis, and growth rate of hybridomas. Journal of Immunological Methods, 79, 263-275. doi:10.1016/0022-1759(85)90106-1

[21] Trump, B.F. and Berezesky, I.K. (1996) The mechanisms of calcium-mediated cell injury and cell death [correcgted]. New Horizons, 4, 139-150.

[22] Orrenius, S., Zhivotovsky, B. and Nicotera, P. (2003) 
Regulation of cell death: The calcium-apoptosis link. Nature Reviews Molecular Cell Biology, 4, 552-565. doi: $10.1038 / \mathrm{nrm} 1150$

[23] Kurland, J.I., Traganos, F., Darzynkiewicz, Z. and Moore, M.A. (1978) Macrophage-mediated cytostasis of neoplastic hemopoietic cells: Cytofluorometric analysis of the reversible cell cycle block. Cellular Immunology, 36, 318-330. doi:10.1016/0008-8749(78)90276-9

[24] Stout, R. D. (1985) Cytostatic activity of in vitro generated macrophages: Evidence for a prostaglandin-independent reversible cytostatic mechanism. Cellular Immunology, 96, 83-103. doi:10.1016/0008-8749(85)90342-9

[25] Dekkers, J., Bayley, P., Dick, J.R., Schwaller, B., Berchtold, M.W. and Greensmith, L. (2004) Over-expression of parvalbumin in transgenic mice rescues motoneurons from injury-induced cell death. Neuroscience, 123, 459466. doi:10.1016/j.neuroscience.2003.07.013

[26] Palmer, E.J., MacManus, J.P. and Mutus, B. (1990) Inhibition of glutathione reductase by oncomodulin. Archives of Biochemistry and Biophysics, 277, 149-154. doi:10.1016/0003-9861(90)90563-E

[27] Lemaire, G., Alvarez-Pachon, F.J., Beuneu, C., Lepoivre, M. and Petit, J.F. (1999) Differential cytostatic effects of NO donors and NO producing cells. Free Radical Biology \& Medicine, 26, 1274-1283. doi:10.1016/S0891-5849(98)00331-1

[28] Chalifour, L.E., Gomes, M.L. and Mes-Masson, A.M. (1989) Microinjection of metallothionein-oncomodulin DNA into fertilized mouse embryos is correlated with fetal lethality. Oncogene, 10, 1241-1246. 